Hydraulic Engineering Repository

Ein Service der Bundesanstalt für Wasserbau

Kester, James G.; Davis, Stanley R. Hydraulic Variables for Scour using HEC-RAS

Verfügbar unter / Available at:

https://hdl.handle.net/20.500.11970/100250

Vorgeschlagene Zitierweise / Suggested citation:

Kester, James G.; Davis, Stanley R. (2010): Hydraulic Variables for Scour using HEC-RAS. In: Burns, Susan E.; Bhatia, Shobha K.; Avila, Catherine M. C.; Hunt, Beatrice E. (Hg.): Proceedings 5th International Conference on Scour and Erosion (ICSE-5), November 7-10, 2010, San Francisco, USA. Reston, Va.: American Society of Civil Engineers. S. 1120-1129. 


\title{
Hydraulic Variables for Scour using HEC-RAS
}

\author{
James G. Kester ${ }^{1}$, P.E. and Stanley R. Davis ${ }^{2}$, M. ASCE, P.E.
}

${ }^{1}$ KCI Technologies, Inc., 936 Ridgebrook Road, Sparks, MD 21152; PH (410) $316-$

7939; email: james. kesterakci.com

${ }^{2}$ Consultant, 706 Capri Road, Arnold, MD 21012; PH (410) 545-8362; email:

sdavis6@sha.state.md.us

\begin{abstract}
The Maryland State Highway Administration, Office of Structures has adopted a proactive approach with respect to the determination of hydraulic variables for computing scour at structures, most notably through the development of the ABSCOUR program (Reference 2). Scour analyses are very sensitive to hydraulic variables and the Office of Structures places great emphasis on the hydraulic model development, both in its ABSCOUR training workshops and in its design reviews. The following lists several areas of concern:
\end{abstract}

- Careful consideration of potential tailwater conditions and their effect on scour.

- Development of reasonable hydraulic water surface profiles through the structure.

- Review of design/check flood flow distributions from HEC-RAS upstream, downstream and at the structure.

The third bullet, which addresses flow distribution, represents the main focus of this paper. Flow distribution has been identified as a key component of the effort to compute realistic scour depths. The Office of Structures asked KCI to develop a procedure within HEC-RAS (Reference 4) involving geometry file adjustments to provide a more reasonable progression of flow from upstream of the approach section, to downstream of the structure. The flow progression is viewed in the context of the left overbank, main channel and right overbank. For instance, percentage change in flow is viewed in the main channel in each successive section such that significant changes are avoided (say $20 \%$ or less change) from one section to the next downstream section. Three (3) typical cases are defined to demonstrate the flow distribution adjustment process. One case (Case 3) is included to explain the process of balancing flow through the bridge versus flow overtopping the roadway. A comparison is made of the flow distribution in a non-adjusted channel reach versus an adjusted channel reach. The significance of these flow distribution adjustments is illustrated by applying Laursen's live-bed scour equation for estimating contraction scour at a bridge. The contraction scour estimate was reduced significantly by making reasonable adjustments to the hydraulic model.

\section{INTRODUCTION}

The focus of this paper is on the development of a reasonable flow distribution for evaluating scour at a bridge. However, three conditions are necessary 
in the use of the approach discussed herein: The first is that one-dimensional flow modeling is appropriate for modeling the structure. (In Maryland, It has been our experience that the great majority of hydraulic models for determining variables for scour are performed using the one-dimensional HEC-RAS model. This is not to say that certain complex flow conditions do not require a two-dimensional model; however, these cases have been relatively rare.) The second is that potential tailwater effects on the structure have been thoroughly investigated. Inaccurate tailwater elevations can have a significant effect on scour results. Often, we have found that tailwater investigations do not extend far enough downstream, specifically on low-gradient streams. Normal depth assumptions for downstream boundary conditions should include a tailwater sensitivity analysis. Downstream control structures such as bridges, culverts and dams should be assessed for their effect on tailwater. Complex hydraulic conditions such as a downstream confluence or tidal flow may necessitate investigating multiple tailwater scenarios. The third condition is that reasonable hydraulic profiles through the structure have been computed. The flow distribution adjustments depend heavily on the hydraulic profiles through the structure as initially computed by HEC-RAS. The discharges in the channel and overbanks through the structure provide the target flow distribution values for the upstream adjustments.

It should be noted that the HEC-RAS flow distribution option does not perform any adjustments to the flow; rather it simply divides the initial flow distribution (based on conveyance) into the number of flow tubes specified by the user. Therefore, flow adjustments as described in this paper are necessary to provide for a reasonable progression of flow. It is emphasized that the adjustment process should be carried out by experienced HEC-RAS users who understand the significance and validity of such adjustments.

\section{Selection of Approach Section}

There are a number of desirable attributes to look for in selecting the location of the approach section: located at a station about one bridge length upstream; located upstream of the contracted flow pattern created by the bridge; representative of the channel and flood plain characteristics of the upstream cross-sections; and selection of a cross-section where the channel flow is essentially parallel to the flood plain (valley) flow. For many stream crossings, and especially for smaller channels, there may not be one section that satisfies all of the above criteria. In such cases, judgment is needed to select the most appropriate section. If there is no desirable section available, it may be helpful to perform a sensitivity analysis by comparing the scour results from two candidate approach sections. This can be accomplished efficiently using the ABSCOUR program.

\section{FLOW DISTRIBUTION ADJUSTMENTS}

The goal of the flow distribution adjustments is to provide a reasonable progression of channel and overbank flows from upstream of the approach section to downstream of the structure. Due to the nature of the flow distribution adjustments, a specific scour plan should be created in HEC-RAS to separate scour hydraulics from 
other hydraulic evaluations such as those intended for permitting purposes. There are three (3) typical flow distribution cases: Case 1 - Bridge abutments located at or near the channel banks, no overtopping of structure; Case 2 - Abutments set back from channel banks, no overtopping of structure and Case 3 - Abutments set back from channel banks, with overtopping of the structure. The following discussion outlines the general flow dsitribution adjustment approach:

1) Target flows, as described in this paper, are the flows in the left overbank, channel and right overbank sections at the bridge as computed by the initial HEC-RAS run. Determine target flow distribution values through the structure using the Flow Distribution Locations option under the steady flow simulation button in HEC-RAS (for abutments that are set back from channel). If abutments are at or near the channel banks, assume $100 \%$ of the flow is in the channel. For overtopping flow, the target values should be adjusted to account for any weir flow that is on the left overbank, channel and right overbank at the structure, dividing the total weir discharge provided by HEC-RAS based on proportions of the weir length. The HEC-RAS prercentage flows in the left overbank, channel and right overbank for Case 3 (with overtopping) are for flow through the bridge only and they must be recomputed based on total discharge (see Case 3 example).

2) Look for trends in the flow distribution that HEC-RAS computes prior to any adjustments by reviewing $\mathrm{Q}$ percent left, $\mathrm{Q}$ percent channel and $\mathrm{Q}$ percent right in a user-defined HEC-RAS table. Look for (1) reasonably consistent flow in the overbanks and the channel for sections upstream of the influence of the structure or (2) a consistent flow contraction that shows flow moving into the channel as it approaches the structure. The latter scenario may require only minor adjustments in the flow distribution.

3) Start flow distribution adjustments several sections above the approach section selected for the scour evaluation. Beginning on overbanks areas, adjust Manning's roughness up or down and/or make the edges of the floodplain ineffective to redistribute flow. Flow prior to the contraction should stay fairly consistent, with percent flow changes between successive sections within an overbank or in the channel that does not exceed 15\%. For larger streams and rivers, a maximum $20 \%$ change may be more appropriate.

4) For a typical flow contraction (Cases 1 and 2), the main channel discharge should steadily increase in the direction of flow as flow is pushed into the channel from the overbanks. Changes to roughness and/or ineffective area limits can be used to achieve this pattern.

5) Overtopping conditions (Case 3 ) need to be carefully considered in terms of the downstream flow distribution since tailwater elevation and the hydraulics of the bridge can be affected. Immediately downstream of the bridge, overbank flow should be limited to the flow overtopping the road and/or bridge. In typical situations, the flow through the bridge cannot expand quickly enough to be effective on the overbanks just below the structure. A blocked obstruction may be used to reflect this condition; that is, reduce the amount of flow in the section immediately downstream of the bridge. To add flow to an overbank area, the 
elevation of the floodplain can be lowered. This may be necessary in a situation where HEC-RAS places all the flow in an incised channel, but overtopping flow on a roadway approach is known to exist.

6) If the bridge hydraulics changes due to the downstream flow distribution adjustments (revised tailwater elevation or flow through the bridge, etc.), a second iteration in the adjustments may be needed to establish new target values (See Example Case 3). If the percent of the total flow that overtops the road is $15 \%$ or less, there probably will not be much of a change in the target values and no changes to the flow distribution would likely be required.

Changes to the HEC-RAS geometry to adjust the flow distribution must be reasonable. For instance, adjustments to Manning's roughness values in the channel or overbank areas must be within the bounds of what could reasonably be expected based on site conditions and engineering judgement. The adjustments should result in relatively minor changes in water-surface elevations as compared with the initial condition.

\section{Sample Case 3 Flow Distribution Adjustments (Abutments set back from channel banks, with overtopping of the structure)}

For illustrative purposes, the following provides a synopsis of the flow distribution approach for Case 3. The HEC-RAS Flow Distribution Output table for the bridge shows flow percentages of $23 \%, 56 \%$ and $21 \%$ respectively for the left overbank, channel and right overbank for the $87 \%$ of the total flow that passes through the bridge ( $13 \%$ overtops road from left overbank). Since the HEC-RAS ouput $(23 \%, 56 \%, 21 \%)$ is for flow through bridge only, the percent of total flow at the bridge (including weir flow) must be computed. Percentages based on total flow (203.9 $\mathrm{cms}$ or $7200 \mathrm{cfs}$ ) are used as target values to adjust the approach flow distribution. Since the overtopping flow is entirely on the left overbank in this example, this overtopping flow percentage of flow is added to the QLOB percentage of flow. If the overtopping flow was distributed over the approaches and bridge deck, the percentage overtopping flow could be divided between the LOB, channel and $\mathrm{ROB}$ based on proportions of total weir length to estimate percent flows. Figure 1 illustrates the bridge target values: 


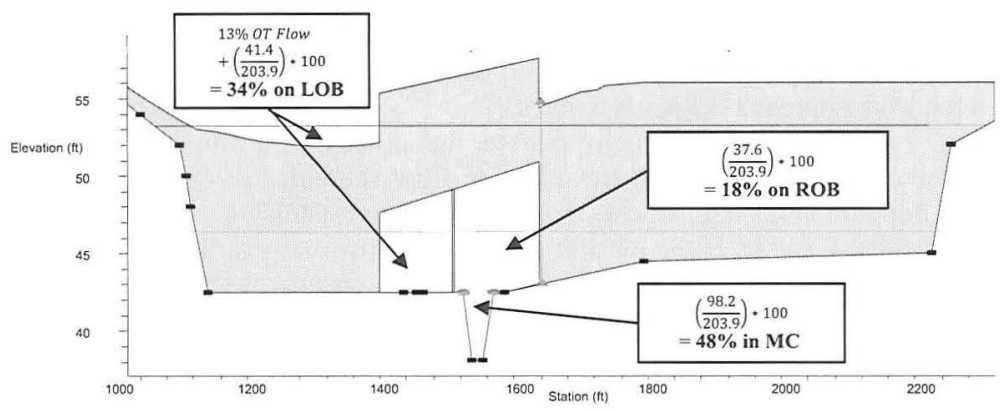

Figure 1 - Bridge Section with Target Values

The flow distribution at the river stations for the initial HEC-RAS run is presented below. Target values of $48 \%$ of the flow in the main channel (MC), 34\% on the left overbank (LOB) and $18 \%$ on the right overbank (ROB) at the bridge was selected as the basis for the flow adjustments in the upstream river stations. Note that this example assumes that the flow distribution upstream of RS 6000 as computed initally by HEC-RAS is reasonable. A comparison of the target values to those determined initally by HEC-RAS upstream of the bridge indicates that some adjustments should be made to provide for a more reasonable progression of flow, as illustrated in Table 1:

Table 1 - Initial Flow Distribution from HEC-RAS

\begin{tabular}{|c|c|c|c|c|}
\hline $\begin{array}{l}\text { River Station } \\
\text { (RS) }\end{array}$ & $\begin{array}{l}\text { Percent } \\
\text { LOB }\end{array}$ & $\begin{array}{l}\text { Percent } \\
\text { MC }\end{array}$ & $\begin{array}{c}\text { Percent } \\
\text { ROB }\end{array}$ & Comments \\
\hline 7000 & 14 & 50 & 36 & Reasonable distribution \\
\hline 6000 & 14 & 50 & 36 & Begin adjustments \\
\hline 5000 & 16 & 31 & 53 & $\begin{array}{l}\text { Too little flow in MC, too } \\
\text { much flow on ROB }\end{array}$ \\
\hline $\begin{array}{l}4500 \text { Approach } \\
\text { XS }\end{array}$ & 25 & 25 & 50 & $\begin{array}{l}\text { Too little flow in } M C \text {, too } \\
\text { much flow on ROB }\end{array}$ \\
\hline 3500 & 47 & 25 & 28 & $\begin{array}{l}\text { Too little flow in } \mathrm{MC} \text {, too } \\
\text { much flow on ROB and LOB }\end{array}$ \\
\hline 2000 & 57 & 32 & 11 & $\begin{array}{l}\text { Too little flow in } \mathrm{MC} \text {, too } \\
\text { much flow on LOB }\end{array}$ \\
\hline 1500 Bridge $X S$ & 34 & 48 & 18 & Bridge Target Values \\
\hline 1000 & 50 & 36 & 14 & $\begin{array}{l}\text { Too little flow in } \mathrm{MC} \text {, too } \\
\text { much flow on LOB }\end{array}$ \\
\hline 100 & 17 & 79 & 5 & $\begin{array}{l}\text { Too much flow in MC, too } \\
\text { litte flow on LOB }\end{array}$ \\
\hline
\end{tabular}


Table 2 provides the initial flow distribution for comparison to the adjusted flow distribution:

Table 2 - Initial Flow Distribution and Adjusted (Adj.) Flow Distribution

\begin{tabular}{|c|c|c|c|c|c|c|}
\hline $\begin{array}{c}\text { River Station } \\
(\mathbf{R S})\end{array}$ & \multicolumn{2}{|c|}{ Percent LOB } & \multicolumn{2}{c|}{ Percent MC } & \multicolumn{2}{c|}{ Percent ROB } \\
\cline { 2 - 7 } & Initial & Adj. & Initial & Adj. & Initial & Adj. \\
\hline 7000 & 14 & - & 50 & - & 36 & - \\
\hline 6000 & 14 & 17 & 50 & 39 & 36 & 44 \\
\hline 5000 & 16 & 20 & 31 & 42 & 53 & 38 \\
\hline 4500 Approach XS & 25 & 23 & 25 & 43 & 50 & 35 \\
\hline 3500 & 47 & 27 & 25 & 49 & 28 & 24 \\
\hline 2000 & 57 & 30 & 32 & 50 & 11 & 20 \\
\hline 1500 BR (Targets) & \multicolumn{7}{|c|}{30} & 51 & & 19 \\
\hline 1000 & 50 & 29 & 36 & 55 & 14 & 16 \\
\hline 100 & 17 & 28 & 79 & 64 & 5 & 8 \\
\hline
\end{tabular}

${ }^{1}$ Note that the target values changed slightly due to decreased bridge tailwater.

The following discusses how the adjustments were made. The simplest approach to redistributing the flow is to make adjustments to Manning's roughness values within HEC-RAS using the Manning's roughness table under Geometric Data. The initial roughness values in the channel or overbank can either be raised to reduce the flow or lowered to increase the flow, resulting in flow being shifted from one portion of the cross section to another. The adjusments were initiated at RS 6000, working in the downstream direction. Notice that Table 1 shows too little flow in the channel from RS 5000 to RS 2000. Therefore, channel roughness values were decreased for these river stations to shift flow to the channel, as shown in Table 3. There is too much flow is on the right overbank from RS 5000 to RS 3500 and roughnesses were raised to shift flow. The end result is that flow was shifted from the right overbank to the channel in order to produce the pattern of the contraction of the flow that is expected to occur. Table 3 highlights the roughness changes that were made to redistribute the flow in this example:

Table 3 - Manning's Roughness Adjustments

\begin{tabular}{|c|c|c|c|c|c|c|}
\hline $\begin{array}{c}\text { River Station } \\
(\text { RS) }\end{array}$ & \multicolumn{2}{|c|}{ ROB } & \multicolumn{2}{c|}{ MC } & \multicolumn{2}{c|}{ LOB } \\
\cline { 2 - 7 } & Initial n & Adj. n & Initial n & Adj. n & Initial n & Adj. n \\
\hline 6000 & 0.1 & 0.08 & 0.04 & 0.05 & 0.1 & 0.08 \\
\hline 5000 & 0.1 & 0.09 & 0.04 & 0.033 & 0.1 & 0.15 \\
\hline 4500 Approach XS & 0.1 & 0.18 & 0.04 & 0.03 & 0.1 & 0.16 \\
\hline 3500 & 0.1 & 0.18 & 0.04 & 0.03 & 0.1 & 0.16 \\
\hline 2000 & 0.1 & 0.18 & 0.04 & 0.031 & 0.1 & 0.08 \\
\hline $1500 B R$ & - & - & - & - & - & - \\
\hline 1000 & 0.12 & 0.12 & 0.04 & 0.035 & 0.12 & 0.14 \\
\hline 100 & 0.12 & 0.08 & 0.04 & 0.055 & 0.12 & 0.08 \\
\hline
\end{tabular}




\section{Ineffective Flow and Blocked Obstructions}

Additional adjustment techniques include moving ineffective flow limits, the placement of blocked obstructions and the lowering of overbank elevations. In this example, an ineffective flow limit was added to RS 3500 to reduce left overbank flow and the right overbank ineffective limit was moved out at RS 2000 to increase flow here. This technique can be used to shift the overbank flow when the desired flow redistribution cannot be achieved solely by changing the Manning " $n$ " roughness. A blocked obstruction was added on the left overbank at the bridge upstream bounding section (RS 2000) to reduce flow. In addition, a blocked obstruction was added on the left overbank at the bridge downstream bounding section (RS 1000) to reduce the flow such that it approximately matched the weir flow over the approach roadway. This situation often occurs when HEC-RAS models approach roadway overtopping. The 1-D HEC-RAS model is unable to recognize the fact that the flow cannot expand quickly enough to make the entire left overbank effective at RS 1000 . Ineffective flow area blocks could also be used.

In some situations where there is overtopping flow, adjustments to the flow distribution downstream of the crossing can change the tailwater on the bridge, which in turn, can change the flow through the bridge. Therefore, the adjusted HEC-RAS flow distribution through the bridge should be checked to see if the target values require revision. For instance, a lower tailwater could increase bridge flow and reduce overtopping flow, thereby altering the target values. This is the main reason for extending the flow distribution adjustments downstream of the crossing, especially in overtopping situations. Finally, lowering floodplain elevations may serve to increase overbank flow. This approach may be helpful at a bridge with overtopping flow where the channel is incised. The HEC-RAS model may indicate that there is no overbank flow, but it is known that overbank flow occurs. Changing ground point elevations represents the least preferred adjustment method due to the potential for water-surface elevation changes that may exceed the minor changes that typically would be seen with the previous techniques.

\section{Case 3 Summary}

The distribution based on the revised (lower) tailwater elevation is still appropriate, since the target values changed only slightly. This is due to the fact that the amount of overtopping flow is fairly low (less than $15 \%$ ). Notice that the channel portion of the flow distribution at the approach section has changed dramatically from the initial condition to the adjusted condition. Table 2 indicates that at the approach section (RS 4500), the channel flow increased significantly from $25 \%$ to $43 \%$ (from $50.9 \mathrm{cms}$ to $86.8 \mathrm{cms}$ or $1798 \mathrm{cfs}$ to $3065 \mathrm{cfs}$ ). The higher approach channel discharge results in a lower scour depth in the channel at the bridge as compared to the scour depth without flow distribution adjustments.

Considering the live-bed contraction scour equation as presented in "Hydraulic Engineering Circular 18" (Reference 3) and assuming k1=0.64 (some suspended bed material discharge): 
$\frac{Y 2}{Y 1}=\left(\frac{Q 2}{Q 1}\right)^{\frac{6}{7}}\left(\frac{W 1}{W 2}\right)^{k 1} \quad Y S=Y 2-Y o$

Initial Flow Distribution: $\frac{Y 2}{4.0}=\left(\frac{98.2}{50.9}\right)^{\frac{6}{7}}\left(\frac{16.8}{13.7}\right)^{0.64}$

$$
Y 2=8.0 \mathrm{~m}
$$

$Y S=8.0-4.6$

$Y s=3.4 m(11.2 \mathrm{ft})$.

Adjusted:

$$
\begin{aligned}
\frac{Y 2}{4.0} & =\left(\frac{102.7}{86.8}\right)^{\frac{6}{7}}\left(\frac{16.8}{13.7}\right)^{0.64} \\
Y 2 & =5.3 m \\
Y S & =5.3-4.5 \\
Y S & =0.8 m(2.5 f t)
\end{aligned}
$$

The primary reason for this change is the decrease in the ratio of the main channel flow ( $\frac{Q 2}{Q 1}$ ) from the initial flow distribution condition to the adjusted condition. For this case, the decrease in the contraction scour depth is very significant. There would be an even greater change in the ABSCOUR computations for abutment scour, since contraction scour is used in the computations for abutment scour.

\section{ABSCOUR VERSION 9}

ABSCOUR 9 is a computer program developed by the Maryland SHA, Office of Structures for evaluating scour at bridges and bottomless arch culverts. The program serves as an analytical tool to assist the user in identifying and utilizing the appropriate bridge geometry, hydraulic factors, stream morphology and soil/rock characteristics to evaluate scour at structure foundations. The program estimates scour for both live-bed and clear-water conditions. It evaluates pressure and contraction scour as well as local pier and abutment scour. The user can also input information regarding lateral channel movement and aggradation/degradation to incorporate these factors into the scour evaluation. For the most part, the equations used in ABSCOUR are based on the methodology developed by the FHWA as presented in HEC-18. A Users Manual for ABSCOUR 9 is included in the Office of Structures "Manual for Hydrologic and Hydraulic Design" (Reference 1). ABSCOUR 9 also provides guidance and help for each cell used in the input menus.

Verification and calibration efforts of the ABSCOUR methodology have been on-going for the last 10 years. These include: 
- Cooperative studies with FHWA, utilizing the J. Sterling Jones Hydraulic Laboratory in McLean, Virginia,

- Cooperative studies with the US Geological Survey using a database of measurements of clear water abutment scour collected at South Carolina Bridges.

- Continuing evaluation of the method within the Office of Structures on a bridge by bridge basis to determine ways and means of improving the accuracy of the results and to facilitate its use by others. The Office of Structures presents periodic workshops on the use of the program.

The accuracy of the answers obtained (scour depths) depends on the accuracy of the input information, the selection of the most appropriate analytical methods available in the program and the user's judgment. The latest version, ABSCOUR 9, along with the "Manual for Hydrologic and Hydraulic Design" is available at no cost at the web site: www.gishydro.und.edu.

\section{Input information}

As discussed earlier in this paper, the most important information for the scour evaluation is a reasonable water surface profile to determine water surface elevations and flow distributions in the approach, bridge and downstream crosssections of the study reach. The Maryland SHA uses the HEC-RAS program for this purpose. The stream morphology report serves to investigate the characteristics of surface soils and the probable types of scour (live-bed or clear-water) for various flood discharges under consideration. It also provides information on the potential for aggradation/degradation and lateral stream movement. The preliminary plans describe the proposed bridge geometry. Borings are taken at each proposed foundation element along with at least one channel boring for information on subsurface conditions. ABSCOUR can consider the effect of up to three layers of soil/rock in evaluating clear-water scour.

\section{Output information}

The program prints a detailed scour report for determining contraction and abutment scour. A separate module serves to estimate pier scour, taking into consideration the extent of contraction scour. The program also prints a complete scour cross-section for the channel and flood plain sections under the bridge. A Utilities module is available for various other items of interest, such as sizing riprap for abutment installations.

\section{Sensitivity Analysis}

A powerful attribute of ABSCOUR is the ability to conduct sensitivity analyses of the input parameters. The user can test the effect of various factors (such as soil particle size) on scour depths and can print out a complete report for each factor in a matter of a few minutes. Over-ride features serve to allow the user to select procedures and parameters for computing scour other than the ones selected by ABSCOUR. The Office of Structures recommends caution in the use of over-rides. This approach is best left to engineers with a practical understanding of the inter- 
relationships of the various factors affecting the computation of scour. Design considerations for scour should include all factors affecting the bridge foundations as discussed in the Manual for Hydrologic and Hydraulic Design.

\section{CONCLUSIONS}

Some bridge owners are concerned that the HEC-18/ABSCOUR 9 methodologies may over-estimate scour depths. Since these methodologies have been developed to evaluate worst-case scour conditions, they can be expected to produce conservative but reasonable results. To assure the results are reasonable, the engineer needs to verify that the appropriate analytical methods are used and that the input parameters are representative of the field conditions. The foregoing discussion relating to developing a HEC-RAS model with a reasonably consistent flow distribution pattern is a good example of what can be done to improve the accuracy of scour estimates. Experienced HEC-RAS users should be able to make flow distribution adjustments in a relatively short time frame, say two to three hours. Other reasons for high estimates of scour may include:

- Over-estimating the design discharge. This may occur in the use of hydrologic models, such as TR-20, if the models are not constructed properly,

- Selection of overly-conservative calibration factors for scour computations,

- Inaccurate measurements/estimates of soil properties,

- Addition of all the various elements of scour (contraction scour, pressure scour, pier scour, channel movement, bend scour, degradation, etc.) to compute total scour when it may not be reasonable to assume that all possible types of scour will occur at the same time. These combinations should be evaluated on a case by case basis.

The Maryland State Highway Administration, Office of Structures has spent considerable time and effort in working with other agencies to evaluate and calibrate the ABSCOUR 9 Program. Careful attention to obtaining accurate input information, and following the guidance in the user's manual should result in reasonable estimates of scour.

\section{REFERENCES}

1) Maryland State Highway Administration, "Manual for Hydrologic and Hydraulic Design", March 2010.

2) Maryland State Highway Administration, ABSCOUR Version 9, Build 2.1, January 2010.

3) U. S. Department of Transportation, Federal Highway Administration, (2001) "Evaluating Scour at Bridges, Fourth Edition" FHWA-IP-90-017, Hydraulic Engineering Circular No. 18.

4) U.S. Army Corps of Engineers, Hydrologic Engineering Center, HEC-RAS River Analysis System Version 4.0.0, March 2008. 